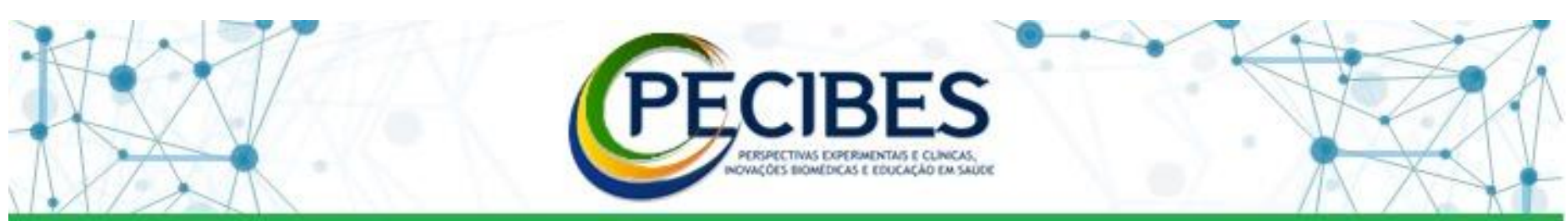

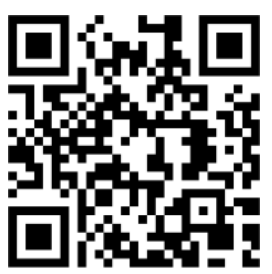

http://www.seer.ufms.br/inde x.php/pecibes/index

* Autor

correspondente:

Patrícia de Morais

Ferreira

Brandão, Universidade

Federal de Mato Grosso do Sul .

UFMS.

E-mail do autor: patriciamorafe@hotm ail.com

Descritores: Acidente Vascular Encefálico. Reabilitação.

Robótica.

Key-words: $\quad$ Stroke. Rehabilitation.

Robotics.

\section{Impacto da terapia robótica no membro superior parético após acidente vascular encefálico: estudo de caso}

Impact of robotic therapy on paretic upper limb after stroke: case study

Patrícia de Morais Ferreira Brandão ${ }^{1}$, Adriana Maria de Oliveira ${ }^{1}$; Carmine Thomas $^{2}$, Henrique Muleta Andrade ${ }^{3}$, Gustavo Christofoletti ${ }^{4},{\text { Alexandre } \text { Morel }^{1}}^{1}$

1. Fisioterapeuta do CER/APAE e mestrando(a) do Programa de Pós-Graduação em Ciências do Movimento do INISA da UFMS, Campo Grande /MS, Brasil.

2. Terapeuta Ocupacional do CER/APAE, Campo Grande/MS, Brasil.

3. Fisioterapeuta, Doutor, Coordenador Técnico do CER/APAE e Pós-Doutorando do Programa de Pós -Graduação em Ciências do Movimento do INISA da UFMS, Campo Grande /MS, Brasil.

4. Fisioterapeuta, Doutor, Orientador e docente do Programa de Pós -Graduação em Ciências do Movimento do INISA da UFMS, Campo Grande /MS, Brasil.

Introdução: O Acidente Vascular Encefálico (AVE) é a primeira causa de incapacidade funcional no mundo. As sequelas podem ser sensitivas, motoras e cognitivas, causando impactos no aspecto físico-funcional, psicológico, social e financeiro. A terapia robótica é um recurso que pode contribuir para a reabilitação de pacientes neurológicos, pois proporciona interação, motivação e prazer na prática de exercícios específicos. Objetivo: Avaliar o impacto da terapia robótica com exoesqueleto Armeo Spring® na amplitude de movimento (ADM) ativa das articulações do membro superior parético de um indivíduo após AVE. Material e métodos: O projeto foi aprovado pelo CEP sob o parecer $\mathrm{n}^{\circ} .781 .801$, de 18/12/2019. Foram realizadas 27 sessões de terapia robótica com duração média de 25 minutos. O Armeo Spring® consiste em uma órtese ajustável de braço onde um mecanismo de mola fornece suporte de peso ajustável, facilitando os movimentos funcionais que são estimulados por meio de jogos virtuais. Os exercícios incluíram jogos que exigiram a movimentação ativa das articulações de ombro, cotovelo e punho, além do movimento de preensão manual. A ADM das articulações foram mensuradas por meio de avaliações do software do próprio dispositivo, onde são calculadas em graus, por meio de sensores, em cada plano de movimento. Estas aconteceram no primeiro, no décimo quarto e no último dia de terapia. Resultados: Houve ganho significativo na ADM ativa das articulações do membro comprometido com predomínio em ombro e cotovelo com destaque nos movimentos de abdução de ombro, onde a variação entre a primeira e a última avaliação chegou a $80^{\circ}$; flexão e extensão de cotovelo, que atingiu $50^{\circ}$; flexão e extensão e rotação interna e externa de ombro, onde ambas alcançaram $30^{\circ} \mathrm{em}$ ganho de amplitude. Conclusão: A terapia robótica com Armeo Spring®, auxiliou na reabilitação do membro superior parético, pois apresentou ganhos de ADM em todas as articulações avaliadas. 